\title{
Early results in the treatment of proximal humeral fractures with a polyaxial locking plate
}

\author{
Johannes B. Erhardt $\cdot$ G. Roderer $\cdot$ K. Grob • \\ T. N. Forster $\cdot$ K. Stoffel $\cdot$ M. S. Kuster
}

Received: 14 January 2008/Published online: 27 June 2009

(C) Springer-Verlag 2009

\begin{abstract}
Objectives We report early results using a second generation locking plate, non-contact bridging plate (NCB $\mathrm{PH}^{\circledR}$, Zimmer Inc. Warsaw, IN, USA), for the treatment of proximal humeral fractures. The $\mathrm{NCB} \mathrm{PH}^{\circledR}$ combines conventional plating technique with polyaxial screw placement and angular stability.

Design Prospective case series.

Setting A single level-1 trauma center.

Patients A total of 50 patients with proximal humeral fractures were treated from May 2004 to December 2005. Intervention Surgery was performed in open technique in all cases.

Main outcome measures Implant-related complications, clinical parameters (duration of surgery, range of motion, Constant-Murley Score, subjective patient satisfaction, complications) and radiographic evaluation [union, implant loosening, implant-related complications and avascular necrosis (AVN) of the humeral head] at 6,12 and 24 weeks.

Results All fractures available to follow-up (48 of 50) went to union within the follow-up period of 6 months. One patient was lost to follow-up, one patient died of a
\end{abstract}

J. B. Erhardt $(\bowtie) \cdot$ K. Grob - T. N. Forster · M. S. Kuster Klinik für Orthopädische Chirurgie, Kantonsspital St. Gallen, 9007 St. Gallen, Switzerland

e-mail: johannes.erhardt@kssg.ch

J. B. Erhardt - K. Stoffel - M. S. Kuster

Fremantle Orthopaedic Unit,

The University of Western Australia,

Perth, WA, Australia

G. Roderer

Abteilung für Unfallchirurgie, Universitätsklinik Ulm,

Ulm, Germany cause unrelated to the trauma, four patients developed AVN with cutout, one patient had implant loosening, three patients experienced cutout and one patient had an axillary nerve lesion (onset unknown). The average age- and gender-related Constant Score $(n=35)$ was 76.

Conclusions The NCB $\mathrm{PH}^{\circledR}$ combines conventional plating technique with polyaxial screw placement and angular stability. Although the complication rate was $19 \%$, with a reoperation rate of $12 \%$, the early results show that the NCB $\mathrm{PH}^{\circledR}$ is a safe implant for the treatment of proximal humeral fractures.

Keywords NCB - Proximal humerus - Fracture · Non-contact bridging · Polyaxial locked plate

\section{Introduction}

Proximal humeral fractures are the third most common fracture after hip and distal radius [19]. Palvanen et al. [19] showed that the incidence and number of these fractures has tripled within the last three decades in Finland and if this trend continues the same can be expected for the future. In particular, a high risk of humeral fracture results from the combination of osteoporosis with an increased risk of falling [16]. The management of proximal humeral fractures has undergone transformation in the recent past due to the emergence of innovative treatment techniques. With the invention of locked plating, a novel biomechanical approach has become available for the stabilization of these fractures $[5,7,24]$. The blood supply to the humeral head [8] prohibits medial positioning of a plate, therefore, early loss of fixation is a commonly reported problem in comminuted and osteoporotic fractures especially [1, 13, 18]. The lateral placement of a locked implant means that 
reduction is maintained by screws that act as struts [9]. Therefore, the indication for osteosynthesis, even for displaced three and four part fractures, has increased in relation to hemiarthroplasty $[11,25]$.

Early results for these locked plates have been published over the last 5 years $[2,11,15,20,22,23]$. The most commonly used implant reported was the Philos ${ }^{\circledR}$ plate (Synthes). The clinical outcomes of various studies involving this implant have been published and they all conclude that it is suitable for use in the treatment of comminuted fractures of the proximal humerus in osteoporotic bone. However, all of them also report a significant number of complications due to screw perforation through the humeral head and, therefore, variable re-operation rates. Different potential solutions have been proposed such as screw augmentation with calcium phosphate cement in combination with both locked and conventional plates [9, 22], limited drilling in osteoporotic bone, the use of blunt-tipped locking screws[21], and locking plates with polyaxial screws like the non-contact bridging plate (NCB, Zimmer)[23]. The NCB combines the properties of conventional and locking plates. In this article, early results and implant-related complications are presented for use of the polyaxial non-contact locking $\left(\mathrm{NCB}^{\circledR}\right)$ plate, a second generation locking device.

\section{Materials and methods}

After approval from the ethics committee had been granted, the first 50 patients to be treated with the $\mathrm{NCB}^{\circledR} \mathrm{PH}$ for an acute traumatic fracture were prospectively enrolled in the study starting in May 2004. Endpoints of the study were the clinical and radiological outcomes and complications after 6 months. Clinical parameters included range of motion (ROM) in flexion and abduction, and the subjective success of the outcome was based on a high, intermediate or poor level of patient satisfaction. Radiological parameters included union/non-union, implant loosening, screw perforation and avascular necrosis (AVN). Exclusion criteria were pathological fractures (caused by neoplasia), hardware failure of other implants whereby the $\mathrm{NCB}^{\circledR} \mathrm{PH}$ was a revision procedure, preoperative axillary nerve damage and inadequate follow-up. Adequate follow-up was considered
Fig. 1 Surgical technique of indirect fracture reduction using the plate as a buttress. Image intensifier images and postoperative X-rays

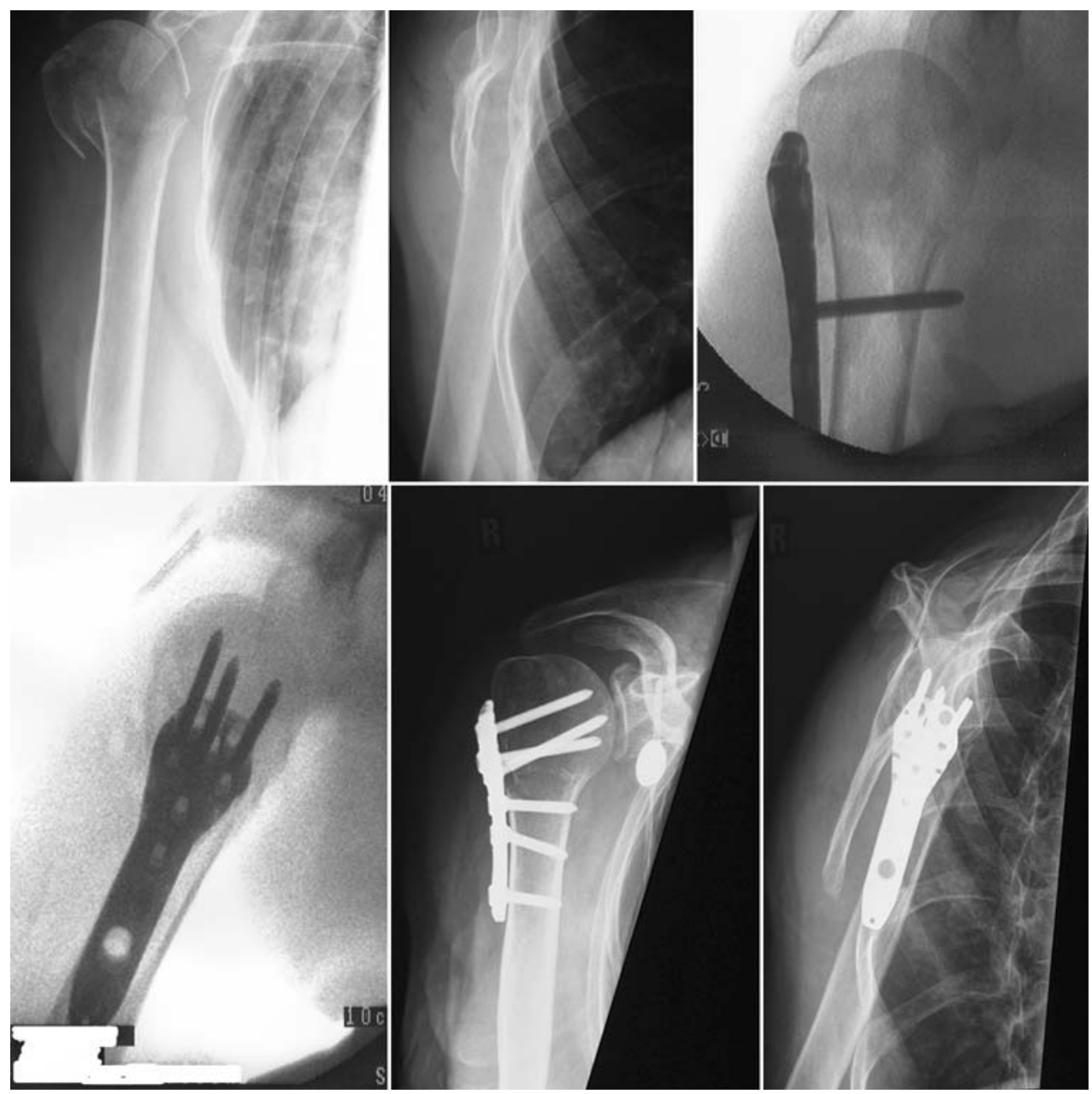


adequate if the patients had documented clinical and radiological healing or had attended all the scheduled follow-up appointments. The follow-up appointments were 6 , 12 and 26 weeks after the surgical procedure. The ConstantMurley score was not included in the initial follow-up protocol. Therefore, after completing the 26-week follow-up, each patient returned again so that their Constant-Murley scores could be obtained [4]. The indications for surgical treatment were all displaced three and four part fractures, type A fractures with varus malalignment and medial comminution, or fractures with almost $100 \%$ displacement (type $\mathrm{A} 2$ and $\mathrm{A} 3$ according to the AO ASIF classification).

Implant and locking mechanism

The plate is a newly designed second generation locked implant, combining the properties of conventional plates with the special features of locked plates. It is available in two versions: a 4- and a 5-hole plate. The plate is suitable for both the left and right sides. It comes with a radiolucent targeting device so that the plate can also be inserted in minimally invasive technique as reported by Roderer et al. [23]. The plate can be used with solid or cannulated screws and $4.0 \mathrm{~mm}$ cortical and $4.5 \mathrm{~mm}$ cancellous screws. This way tactile feedback on the quality of the bone is still given, in contrast to other locking mechanisms. Secondarily, the screws can be locked with the NCB locking screw with a torque of $4 \mathrm{Nm}$ and up to an angle of a total of $30^{\circ}$. This, in contrast to other locking mechanisms, provides no absolute angular stability. In the study presented here failure of the locking mechanism was not reported in contrast to published data of failure of an absolute angular stable implant $[2,9]$. The plate has oblique $2 \mathrm{~mm}$ holes for the reattachment of the rotator cuff.

\section{Surgical technique}

The method of choice was open reduction through a deltopectoral approach in all patients. As proposed by Hertel [12], the reduction of the fracture was performed indirectly without dissecting the single fractured parts whenever possible. Initially all three rotator cuff tendons were held with non-resorbable sutures. In the majority of cases, good reduction can be achieved by applying axial traction on the humerus and pulling the rotator cuff, e.g. the greater and lesser tubercles in an anterior-inferior direction, supplemented by use of the $\mathrm{NCB}^{\circledR}$ as an indirect reduction tool and insertion of compression screws as illustrated in Fig. 1. After reduction, the head screws were placed polyaxially and as divergently as possible and then locked. This was essential in cases of medial comminution. Finally, the sutures were fixed through the $2 \mathrm{~mm}$ oblique holes in the plate.

\section{Postoperative regimen}

In this series, all patients underwent an early passive mobilization regimen. All patients were treated with a restraining shoulder bandage for at least 4 weeks. In the first 2 weeks, single pendulum exercises with passive mobilization up to $30^{\circ}$ were allowed with an increased range of $90^{\circ}$ in the third week. In the fourth week, active mobilization without weight was performed and, finally, in the sixth week full active mobilization was allowed.

\section{Outcome parameters}

Data were collected with regard to demographics, operative details, and the duration of inpatient stay. Clinical and radiological follow-up took place at 6,12 and 26 weeks. The patients were assessed at the 6-, 12- and 26-week follow-ups radiologically and clinically (total shoulder movement in flexion and abduction, subjective success of the outcome with a high, moderate or poor level of satisfaction). Radiographic evaluation included union, implant loosening, hardwarerelated complications and AVN of the humeral head. Union was defined in terms of the patient reporting no shoulder pain or only mild activity-related pain and having no loss of initial fracture reduction or evidence of implant loosening, breakage, combined with evidence of internal or external callus formation [22]. The Constant-Murley score was not included in the initial follow-up protocol. Therefore, after the patients had completed the 26-week follow-up, they were all invited back so that a Constant-Murley score could be obtained [4].

For analysis of change of ROM from 6 to 26 weeks, an independent samples $t$ test was performed using the

Table 1 The demographics of patients and fractures

\begin{tabular}{|c|c|c|}
\hline Mean age in years (range) & $61(25-91)$ & \\
\hline Sex & 20 Males & 30 Females \\
\hline Affected side & 20 Right & 30 Left \\
\hline \multirow{3}{*}{$\begin{array}{l}\text { Fracture classification } \\
\text { AO/ASIF }\end{array}$} & Type A & 11 \\
\hline & Type B & 21 \\
\hline & Type C & 19 \\
\hline $\begin{array}{l}\text { Average length of surgery } \\
\text { in min }( \pm S D)\end{array}$ & $76 \pm 29$ & \\
\hline $\begin{array}{l}\text { Average length of } \\
\text { hospital stay in days } \\
( \pm \text { SD })\end{array}$ & $7 \pm 4$ & \\
\hline $\begin{array}{l}\text { Mean follow-up in } \\
\text { months (range) }\end{array}$ & $10(3-22)$ & \\
\hline \multicolumn{3}{|l|}{ Injury mechanism } \\
\hline Body height fall & 39 & \\
\hline Road traffic accident & $\begin{array}{l}2 \text { Bicycles, } 4 \\
\text { motorbikes, } 3 \text { cars }\end{array}$ & \\
\hline Sport & 2 While skiing & \\
\hline
\end{tabular}


Fig. 2 Functional results of flexion and abduction at 6 weeks, 3 months and 6 months after the surgical intervention. The increase in the range of motion between each follow-up was significant $(p<0.05)$

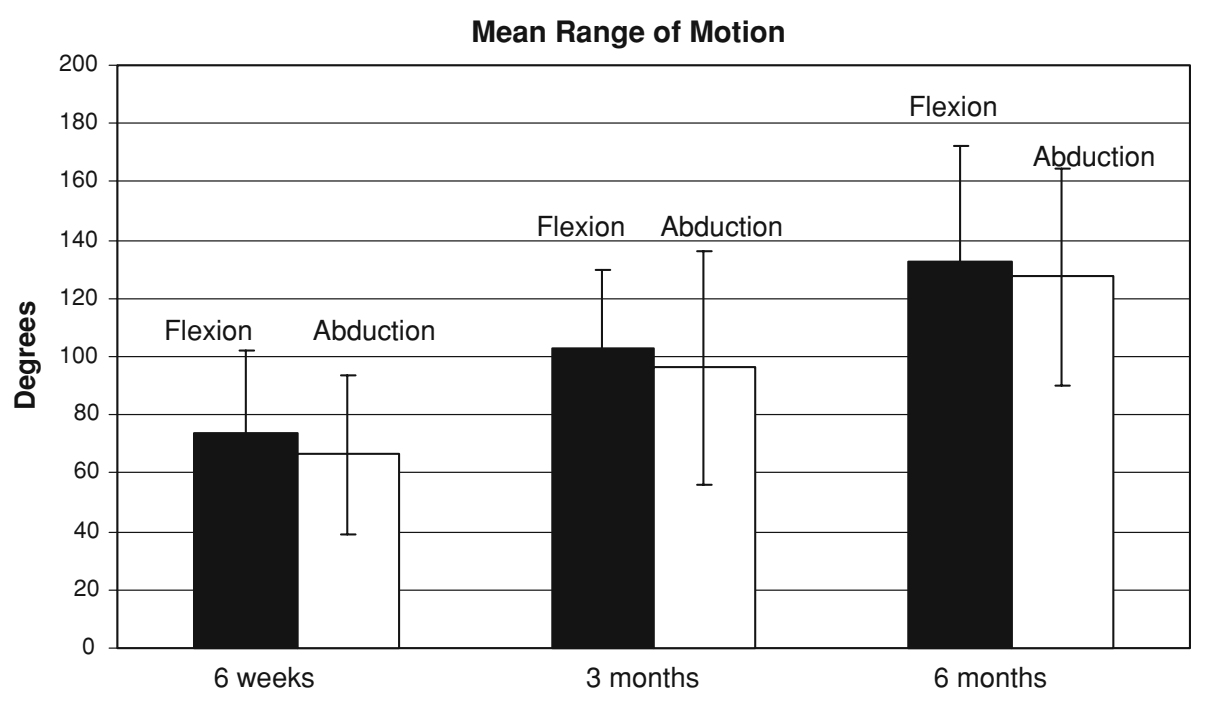

Fig. 3 Results of the RawConstant-Murley Score $( \pm \mathrm{SD})$ after an average follow-up period of 10 months. The average score was $66 \pm 16$ in $n=35$ patients. The table shows the four sections of the score including pain, activities of daily life (ADL), range of motion (ROM), and strength

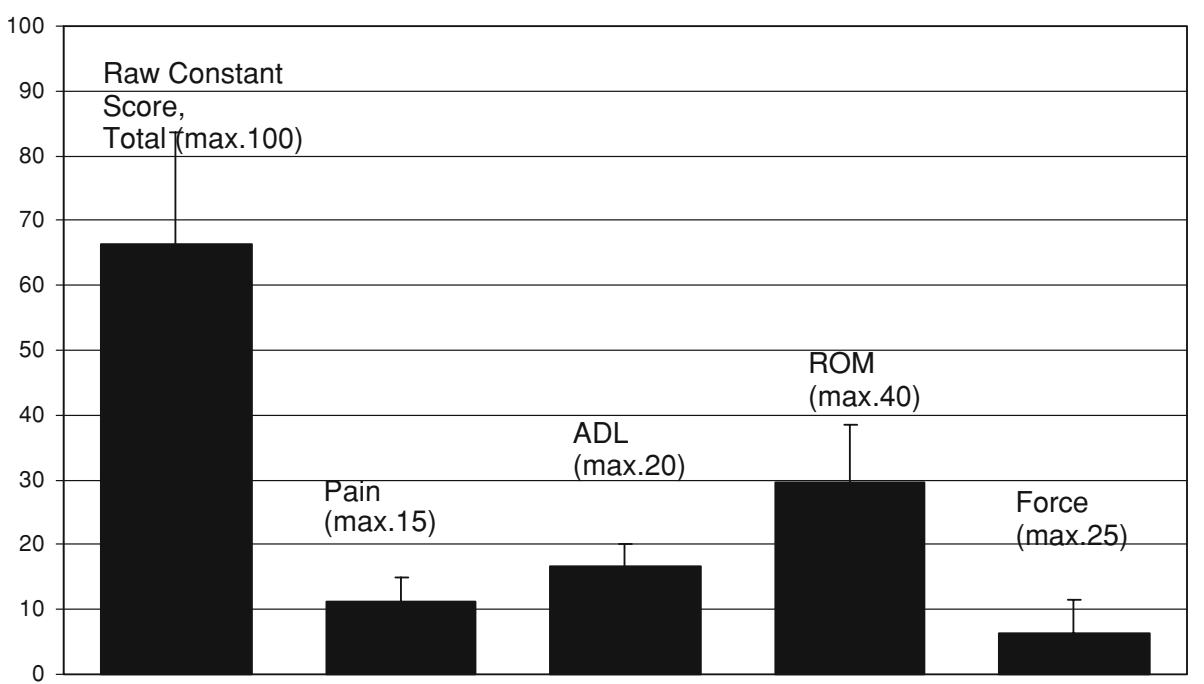

software SSPS 15.0 for Windows with a significance threshold of $p<0.05$.

\section{Results}

Clinical and radiological follow-up was possible for 48 of 50 patients. One patient failed to attend any of the followup appointments and the second patient died of a cause unrelated to the trauma. The fractures united in all 48 patients available for clinical and radiological follow-up. The shortest follow-up period was 3 months; this patient was content with documented clinical and radiological healing and did not want to attend any further appointments. The demographics of the patients and the fractures are shown in Table 1.

No adverse events were reported with regard to the surgical procedure. The adjacent joints were mobilized during the inpatient stay whereby, in this case series, early mobilization of the shoulder was performed in a very conservative way with just swinging the arm for 2 weeks and then starting passive mobilization to $90^{\circ}$. The results for average flexion and abduction (with free scapula) are shown in Fig. 2.

After completion of the initial follow-up protocol all patients were invited for Constant-Murley scoring [4] after a minimum of 6 months, postoperatively. Thirty-five patients attended this appointment. The average follow-up period at this stage was 10 months. The average age of these patients was 70 (47-91) years. According to the study of Katolik [14] an age- and gender-related Constant Score was calculated using the formula: (raw score/normal score $) \times 100$. We used the normal scores as presented in the series of Katolik [3, 14], which are higher values than those Constant described initially. Therefore, the risk of overestimating shoulder function is decreased. The results 
Table 2 Patient data including age, gender, raw Constant score and age- and gender-related Constant Score

\begin{tabular}{|c|c|c|c|c|}
\hline Patient & Age & Gender & $\begin{array}{l}\text { Raw Constant } \\
\text { Score }\end{array}$ & $\begin{array}{l}\text { Age/gender-related } \\
\text { Constant Score }\end{array}$ \\
\hline 1 & 47 & M & 93 & 97 \\
\hline 2 & 79 & $\mathrm{~F}$ & 65 & 80 \\
\hline 3 & 84 & $\mathrm{~F}$ & 75 & 93 \\
\hline 4 & 59 & M & 86 & 91 \\
\hline 5 & 59 & F & 69 & 82 \\
\hline 6 & 74 & $\mathrm{~F}$ & 74 & 91 \\
\hline 7 & 47 & M & 60 & 63 \\
\hline 8 & 77 & $\mathrm{~F}$ & 41 & 51 \\
\hline 9 & 64 & M & 81 & 88 \\
\hline 10 & 75 & M & 74 & 91 \\
\hline 11 & 57 & $\mathrm{~F}$ & 38 & 45 \\
\hline 12 & 68 & $\mathrm{~F}$ & 60 & 72 \\
\hline 13 & 72 & F & 81 & 100 \\
\hline 14 & 58 & M & 70 & 74 \\
\hline 15 & 58 & M & 89 & 95 \\
\hline 16 & 65 & M & 84 & 91 \\
\hline 17 & 64 & M & 45 & 49 \\
\hline 18 & 48 & $\mathrm{~F}$ & 67 & 78 \\
\hline 19 & 72 & $\mathrm{~F}$ & 80 & 99 \\
\hline 20 & 75 & $\mathrm{~F}$ & 80 & 99 \\
\hline 21 & 68 & M & 45 & 49 \\
\hline 22 & 75 & $\mathrm{~F}$ & 52 & 64 \\
\hline 23 & 49 & M & 74 & 77 \\
\hline 24 & 61 & M & 88 & 96 \\
\hline 25 & 75 & M & 73 & 83 \\
\hline 26 & 83 & $\mathrm{~F}$ & 53 & 65 \\
\hline 27 & 63 & $\mathrm{~F}$ & 78 & 94 \\
\hline 28 & 81 & $\mathrm{~F}$ & 57 & 70 \\
\hline 29 & 76 & $\mathrm{~F}$ & 52 & 64 \\
\hline 30 & 88 & $\mathrm{~F}$ & 35 & 43 \\
\hline 31 & 86 & $\mathrm{~F}$ & 57 & 70 \\
\hline 32 & 90 & $\mathrm{~F}$ & 45 & 56 \\
\hline 33 & 91 & $\mathrm{~F}$ & 66 & 81 \\
\hline 34 & 90 & $\mathrm{~F}$ & 40 & 49 \\
\hline 35 & 57 & $\mathrm{~F}$ & 66 & 79 \\
\hline
\end{tabular}

showing an average raw score of $66 \pm 16$ are presented in Fig. 3. Patient data and the calculated age- and genderrelated Constant Score of $76 \pm 18$ are given in Table 2 .

In addition, the subjective level of satisfaction was evaluated and recorded in three stages. Thirty-eight patients showed high satisfaction at the final follow-up, eight patients were moderately satisfied, and two patients were dissatisfied with the treatment outcome. Implants were removed from four patients because of an impingement syndrome.
Complications

During the follow-up period the complication rate was $18.7 \%$ (9 of 48 cases). Partial axillary nerve palsy was reported in one case $(2 \%)$. The patient with a history of cervical fusion could not remember whether the palsy was already present before the surgical intervention, but because it was not clearly reported in the medical and emergency department chart, we assumed it to be a complication. In three patients $(6.2 \%)$, cutout of at least one screw through the humeral head into the joint was noted within the first 6 weeks so that either removal of some implants or replacement of at least one screw was required (Fig. 4). With reference to the AO ASIF classification, these complications occurred in 2 type $\mathrm{C}$ fractures and 1 type A fracture with $100 \%$ displacement. In four patients (8.3\%) partial AVN developed, which led in all cases to screw perforation of the humeral head, requiring partial or complete implant removal in three patients. The AO ASIF classifications in these cases were 2 type C, 1 type B and 1 type A with $100 \%$ displacement. Implantation of a prosthesis was not necessary in any of these cases. Finally, in one (2\%) 91-year-old demented non-compliant patient, the plate loosened during the inpatient stay leading to loss of reduction of the humeral head. In the further course this was managed non-surgically. In summary, the complication rate was $18.7 \%$ ( 9 of 48 cases) with a re-operation rate of $12.5 \%$ during the follow-up period (Table 3 ).

\section{Discussion}

The treatment modalities for proximal humeral fractures have increased since the introduction of fixed angled devices. The introduction of these devices has encouraged surgeons to decide in favor of surgical treatment, in general, and osteosynthesis rather than a prosthesis, in particular [25]. However, non-surgical management of these fractures still dominates in the majority of cases [10, 25]. Because of the increasing incidence of this type of injury [19] and the increasing demands on shoulder function at an older age, the number of patients receiving surgical treatment will increase in the future.

This article is based on the first 50 cases prospectively enrolled and treated at our institution since the introduction of the $\mathrm{NCB}^{\circledR}$ humeral plate in 2004.

Early clinical results show good clinical outcome with variable complication rates $[2,6,11,15,20,22,23]$ for the locked plates. However, these authors all report a significant number of complications due to screw perforation through the humeral head. A complication occurring more commonly since the introduction of locked implants is the cutout of screws through the 

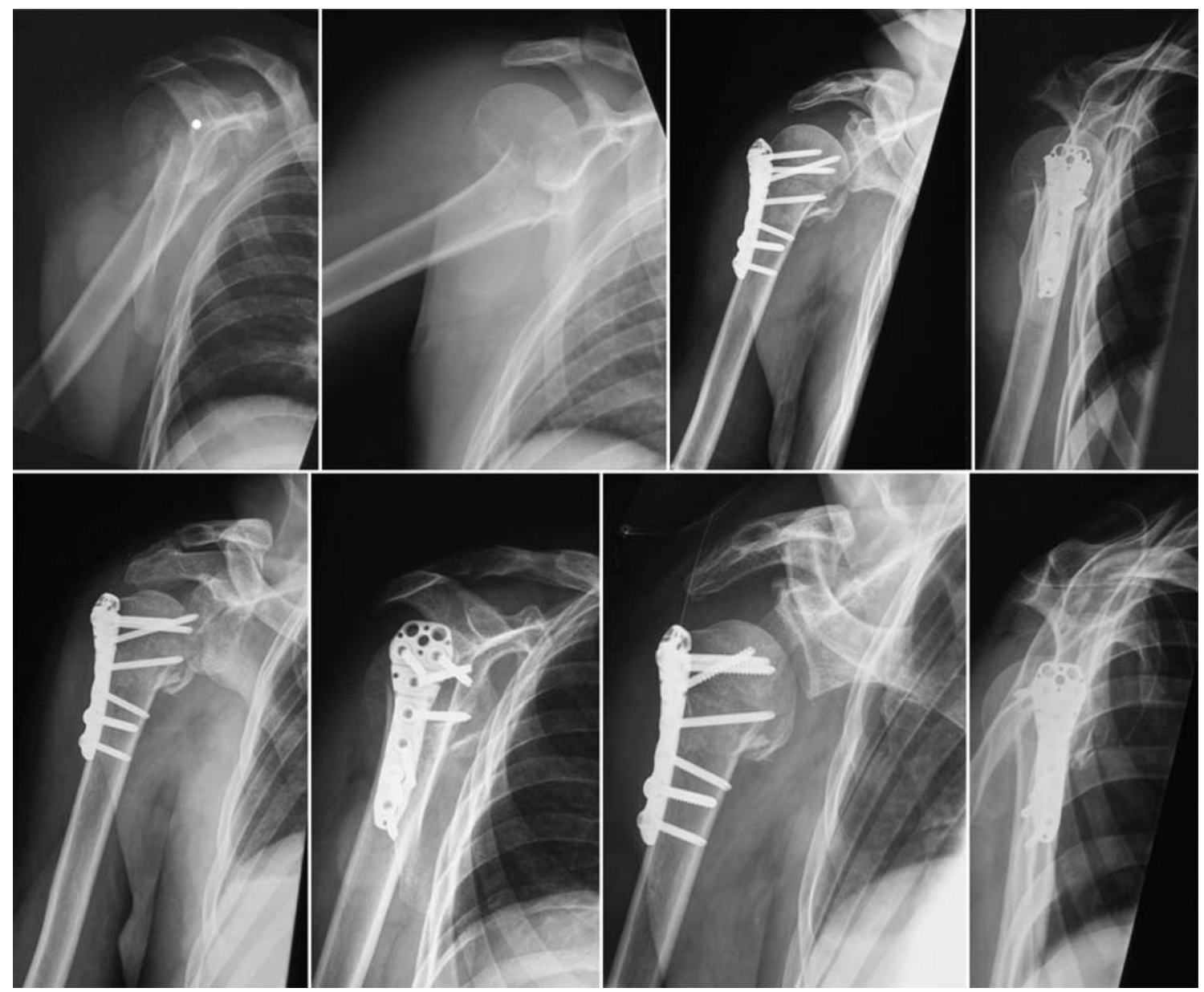

Fig. 4 These radiographs show the radiological course of an AO ASIF 11 C2 fracture in a 47-year-old male. At the 6-week follow-up, cutout of one screw was visible in the glenohumeral joint and

Table 3 Complications seen in $18.7 \%$ ( 9 of 48) patients treated with the NCB PH for an acute proximal humeral fracture

\begin{tabular}{lll}
\hline $\begin{array}{l}\text { Partial axillary nerve palsy } \\
\begin{array}{l}\text { Cutout of screw in the } \\
\text { glenohumeral joint }\end{array}\end{array}$ & $\begin{array}{l}1(2 \%) \\
\text { without AVN }\end{array}$ & $\begin{array}{l}\text { AO/ASIF } \\
2 \text { Type C, 1 Type A }\end{array}$ \\
$\begin{array}{l}\text { Cutout of screw in the } \\
\text { glenohumeral joint with } \\
\text { partial AVN }\end{array}$ & $4(8.3 \%)$ & $\begin{array}{l}\text { AO/ASIF } \\
2 \text { Type C, 1 Type B, } \\
1 \text { Type A }\end{array}$ \\
$\begin{array}{l}\text { Loosening of implant and } \\
\text { loss of fixation }\end{array}$ & $1(2 \%)$ & 1 AO/ASIF Type C \\
\hline
\end{tabular}

calvarium because of the inability to fix the head fragment in position until fracture healing is completed. This risk seems to be especially great if the medial hinge is not restored by reduction or, alternatively, by insertion of an inferior-medial locking screw [9]. Charalambous et al. [2] report a series of 25 cases treated with the Philos ${ }^{\circledR}$ plate. They present 17 acute cases and 8 cases treated after delayed or non-union, or previous hardware failure. conversion to a shorter screw was performed. Ten months after the injury the Constant score was 60

They reported 15 complications in the acute group and 5 in the other group. In total, $20 \%$ of the cases needed surgical revision. In the largest case series to date, Kettler et al. [15] reported an overall complication rate of $37 \%$ (65 of 176) with primary or secondary "cut out" phenomena or implant loosening in 26\% (46 of 176) in a case series of 225 (176 available to follow-up) with a reoperation rate of $16.4 \%$. At the end of the study, 47 plates had been removed. Furthermore, several authors have reported plate breakage, failure of the locking mechanism, and backing up of locked screws [2, 6, 15] for the Philos plate. For the $\mathrm{NCB}^{\circledR} \mathrm{PH}$ Roderer et al. [23] reported a slightly decreased rate of complications at around $23 \%$ in a case series of 61 patients using a minimally invasive technique, with a re-operation rate of $17 \%$, not including the plate removals ( 3 patients) due to impingement. These results are similar to those we present for the $\mathrm{NCB}^{\circledR}$ using a delto-pectoral approach and open reduction technique with a complication rate of $18.7 \%$ and a re-operation rate of $12.5 \%$. 
Including our own patients treated with the $\mathrm{NCB}^{\circledR}$, no plate breakage or failure of the locking mechanism has been reported to date. This might be because the NCB Plate is slightly thicker than other plates and the locking mechanism with locking cap offers more resistance to backing out of screws. Whether the absence of reported screw breakages is thanks to the thicker screw diameter of $4.5 \mathrm{~mm}$ compared to other implants or to the design of the locking mechanism is not absolutely clear. It is also not clear whether this relative angular stability plays a beneficial role in reducing the rate of screw perforations into the joint. Another feature which might have an influence on the rate of screw perforations into the joint is the thicker screw diameter and the option of using cancellous screws.

The specific advantages of polyaxiality in combination with the locking mechanism are that during drilling and screw insertion the feel for bone quality is preserved and the screw can be directed into an area of good bone and then locked afterwards. Polyaxiality also facilitates the positioning of an infero-medial screw as described by Gardner [9].

Even if biomechanical data is confirming the benefits of elastic properties in the fixation stability of locked plates compared to nails and conventional plates [17], no recommendations have yet been validated by biomechanical data on how to position the screws in the humeral head to achieve maximal fixation stability, especially with polyaxial second generation locking plates.

A limitation of this study is that this case series only yields preliminary results with an endpoint of the study after 6 months. Even though the clinical and radiological follow-up rate was $96 \%$ a Constant-Murley score was only obtained for $72 \%$ of the patients. However, without exception all fractures united during the follow-up period in the patients available to follow-up (48 of 50) and, in our experience, implant-related complications generally occur in the early postoperative period. It is not possible to comment on the later development of total or partial AVN, whereby the rate of $8.3 \%$ recorded for our series is much lower than the rate of $16 \%$ obtained by Hente et al. [11] in their series for a similar distribution of fracture patterns. This might be related to the short follow-up period. Another limitation of this study is the lack of a comparative group. On the basis of the prospective follow-up of the first 50 cases, it is certainly a reliable documentation of the treatment outcomes that can be achieved in a cohort comprised of $83 \%$ AO ASIF type B or C proximal humeral fractures when these are managed by application of a second generation locking device. This report also provides an almost complete picture of this prospective case series since the "fate" of only one implant is unknown.

As various authors state, no prospective clinical trials have been conducted to date to compare locked implants with polyaxial locked implants or even conventional plates or non-surgical treatment [10]. The treatment of proximal humeral fractures remains a challenge despite the expansion of treatment options since the introduction of locked plates. There is still great potential to improve the outcomes, especially in terms of decreasing the rates of fixation failure and cutout.

\section{References}

1. Bathis H, Tingart M, Bouillon B, Tiling T (2001) Surgical treatment of proximal humeral fractures. Is the T-plate still adequate osteosynthesis procedure? Zentralbl Chir 126(3):211216. doi:10.1055/s-2001-12498

2. Charalambous CP, Siddique I, Valluripalli K, Kovacevic M, Panose P, Srinivasan M, Marynissen H (2007) Proximal humeral internal locking system (PHILOS) for the treatment of proximal humeral fractures. Arch Orthop Trauma Surg 127(3):205-210. doi:10.1007/s00402-006-0256-9

3. Constant CR (1997) An evaluation of the Constant-Murley shoulder assessment. J Bone Joint Surg Br 79(4):695-696

4. Constant CR, Murley AH (1987) A clinical method of functional assessment of the shoulder. Clin Orthop Relat Res 214:160-164

5. Edwards SL, Wilson NA, Zhang LQ, Flores S, Merk BR (2006) Two-part surgical neck fractures of the proximal part of the humerus. A biomechanical evaluation of two fixation techniques. J Bone Joint Surg Am 88(10):2258-2264. doi:10.2106/JBJS.E.00757

6. Fankhauser F, Boldin C, Schippinger G, Haunschmid C, Szyszkowitz R (2005) A new locking plate for unstable fractures of the proximal humerus. Clin Orthop Relat Res 430:176-181. doi:10.1097/01.blo.0000137554.91189.a9

7. Gardner MJ, Griffith MH, Demetrakopoulos D, Brophy RH, Grose A, Helfet DL, Lorich DG (2006) Hybrid locked plating of osteoporotic fractures of the humerus. J Bone Joint Surg Am 88(9):1962-1967. doi:10.2106/JBJS.E.00893

8. Gardner MJ, Voos JE, Wanich T, Helfet DL, Lorich DG (2006) Vascular implications of minimally invasive plating of proximal humerus fractures. J Orthop Trauma 20(9):602-607. doi: 10.1097/01.bot.0000246412.10176.14

9. Gardner MJ, Weil Y, Barker JU, Kelly BT, Helfet DL, Lorich DG (2007) The importance of medial support in locked plating of proximal humerus fractures. J Orthop Trauma 21(3):185-191. doi:10.1097/BOT.0b013e3180333094

10. Helmy N, Hintermann B (2006) New trends in the treatment of proximal humerus fractures. Clin Orthop Relat Res 442:100-108. doi:10.1097/01.blo.0000194674.56764.c0

11. Hente R, Kampshoff J, Kinner B, Fuchtmeier B, Nerlich M (2004) Treatment of dislocated 3- and 4-part fractures of the proximal humerus with an angle-stabilizing fixation plate. Unfallchirurg 107(9):769-782. doi:10.1007/s00113-004-0818-7

12. Hertel R (2005) Fractures of the proximal humerus in osteoporotic bone. Osteoporos Int 16(Suppl 2):S65-S72. doi: 10.1007/s00198-004-1714-2

13. Hessmann M, Baumgaertel F, Gehling H, Klingelhoeffer I, Gotzen L (1999) Plate fixation of proximal humeral fractures with indirect reduction: surgical technique and results utilizing three shoulder scores. Injury 30(7):453-462. doi:10.1016/S0020-1383 (99)00111-4

14. Katolik LI, Romeo AA, Cole BJ, Verma NN, Hayden JK, Bach BR (2005) Normalization of the Constant score. J Shoulder Elbow Surg 14(3):279-285. doi:10.1016/j.jse.2004.10.009 
15. Kettler M, Biberthaler P, Braunstein V, Zeiler C, Kroetz M, Mutschler W (2006) Treatment of proximal humeral fractures with the PHILOS angular stable plate: presentation of 225 cases of dislocated fractures. Unfallchirurg 109(12):1032-1040. doi: 10.1007/s00113-006-1165-7

16. Lee SH, Dargent-Molina P, Breart G (2002) Risk factors for fractures of the proximal humerus: results from the EPIDOS prospective study. J Bone Miner Res 17(5):817-825. doi: 10.1359/jbmr.2002.17.5.817

17. Lill H, Hepp P, Korner J, Kassi JP, Verheyden AP, Josten C, Duda GN (2003) Proximal humeral fractures: how stiff should an implant be? A comparative mechanical study with new implants in human specimens. Arch Orthop Trauma Surg 123(2-3):74-81

18. Meier RA, Messmer P, Regazzoni P, Rothfischer W, Gross T (2006) Unexpected high complication rate following internal fixation of unstable proximal humerus fractures with an angled blade plate. J Orthop Trauma 20(4):253-260. doi:10.1097/ 00005131-200604000-00004

19. Palvanen M, Kannus P, Niemi S, Parkkari J (2006) Update in the epidemiology of proximal humeral fractures. Clin Orthop Relat Res 442:87-92. doi:10.1097/01.blo.0000194672.79634.78
20. Plecko M, Kraus A (2005) Internal fixation of proximal humerus fractures using the locking proximal humerus plate. Oper Orthop Traumatol 17(1):25-50. doi:10.1007/s00064-005-1120-8

21. Ring D (2007) Current concepts in plate and screw fixation of osteoporotic proximal humerus fractures. Injury 38(Suppl 3):S59-S68. doi:10.1016/j.injury.2007.08.013

22. Robinson CM, Page RS (2004) Severely impacted valgus proximal humeral fractures. J Bone Joint Surg Am 86-A(Suppl 1(Pt 2)):143-155

23. Roderer G, Gebhard F, Erhardt J, Abouelsoud M, Kinzl L (2007) The non-contact bridging plate: a new fixed-angle device for the minimally-invasive treatment of fractures of the proximal humerus-technique and preliminary results. Unfallchirurg 110(6):505-512

24. Seide K, Triebe J, Faschingbauer M, Schulz AP, Puschel K, Mehrtens G, Jurgens C (2007) Locked vs. unlocked plate osteosynthesis of the proximal humerus - a biomechanical study. Clin Biomech (Bristol, Avon) 22(2):176-182. doi:10.1016/j. clinbiomech.2006.08.009

25. Vallier HA (2007) Treatment of proximal humerus fractures. J Orthop Trauma 21(7):469-476. doi:10.1097/BOT.0b013e318133479c 